\title{
AMPHIBDELLID (MONOGENEAN) PARASITES OF ELECTRIC RAYS (TORPEDINIDAE)
}

\author{
By J. Llewellyn, D.Sc. \\ Department of Zoology and Comparative Physiology, University of Birmingham
}

(Plates I-III and Text-figs. I-28)

Electric rays (Torpedinidae) are known to harbour on their gills certain monogenean parasites (Amphibdella spp. and Amphibdelloides spp.) whose taxonomy is in a very confused state. Much of this confusion has centred around a single morphological feature: a 'transverse bar' has been variously held to be present or absent from the adhesive apparatus, or sometimes two such bars have been stated to be present. Among those who have regarded the transverse bar as having taxonomic importance, Price (1937) recognized two genera of amphibdellids distinguishable by the presence or absence of the bar, but Palombi (1949) and Bychowsky (1957) believe that the bar may be present in young specimens but absent or inconspicuous in older specimens. No-one has investigated the function of this transverse bar, or, indeed, any functional aspect of the adhesive apparatus. Again little attention has been paid in taxonomy to the genitalia or host specificity, or, in spite of a record of an amphibdellid from the heart of its host, to micro-habitat.

As part of an attempt to repair these omissions, a general watch was kept for electric rays landed by the research vessels at Plymouth in July and August in the period 1953-59. During this time only three specimens of Torpedo nobiliana were brought in, but fortunately these yielded supplies of the parasites in question. In addition, as a result of the most helpful cooperation on the part of the Staff of the Plymouth Laboratory, especially $\mathrm{Mr}$ J. E. Green, fresh gills of a further two specimens of $T$. nobiliana were sent to Birmingham in October 1956 and September 1959, respectively, and were found to bear living parasites.

Amphibdellids were collected from three distinct micro-habitats on $T$. nobiliana, and for reasons to be given later (pp. 580-5) were identified as follows:

I. Secondary gill lamellae (see Pl. I, fig. 2)

2. Parietal mucosa of gills (see P1. I, fig. I)

3. Cavity of heart
Amphibdelloides maccallumi (Johnston \& Tiegs, 1922) Price, 1937

Amphibdella flavolineata MacCallum, I916. Adult specimens

A. flavolineata MacCallum, 1916. Juvenile specimens

JOURN. MAR. BIOL. ASSOC. VOL. 39, 1960 
Amphibdelloides maccallumi was found to be very common, some 1oo to over 2000 specimens being present on each of the five host specimens examined; adult specimens of Amphibdella flavolineata were found on the gill mucosa of four of the five host specimens, the maximum infestation being six parasites per host; and juvenile specimens of $A$. flavolineata were found in the heart of two host specimens, one of these hosts bearing two parasites, and the other a single parasite.

All these parasites were studied living and in situ, as living specimens under pressure of a cover-glass, as stained whole mounts, and by means of paraffin sections. In studying the adhesive apparatus, whole specimens relaxed in propylene phenoxetol (Owen, 1955), mounted freely in glycerol, and examined stereoscopically, were especially useful, as also was phase-contrast microscopy of flattened whole mounts in balsam.

These monogenean parasites of Torpedo nobiliana at Plymouth have been compared with various amphibdellid parasites from electric rays from other regions as indicated in Table $\mathrm{I}$, in which the hosts have been named as in Bigelow \& Schroeder (1953). As a result of the comparison it became necessary to propose certain taxonomic revisions. For convenience these are listed in Table I but the taxonomic diagnoses will be given later (pp. 580-2) following descriptions of the kinds of characters used in the recognition of the different species.

\section{MICRO-HABITAT}

Amphibdelloides maccallumi lies between two adjacent secondary gill lamellae (P1. I, fig. 2) with its posterior end in contact with the primary lamella (P1. II, fig. I). It maintains this position by the use of two pairs of hooks, one pair directed dorsally and the other ventrally. These hooks are inserted into the bases of the secondary lamellae, the points of the hooks often emerging on the other side of the lamella.

Adult specimens of Amphibdella flavolineata attach themselves to the proximal region of a primary gill lamella, i.e. a region adjacent to the interbranchial septum and lacking secondary lamellae (P1. I, fig. I), and referred to in Torpedo torpedo by Parona \& Perugia (1890, p. 364) as 'mucosa parietale'. The whole of the relatively bulky haptor is accommodated subcutaneously within the host tissues, the remainder of the body of the parasite being connected to the haptor by a neck region which is constricted by the superficial 'tissues of the host (Pl. II, fig. 2).

Amphibdelloides vallei attaches itself to the gills of Torpedo marmorata (Pl. I, fig. 3) in exactly the same manner as does its counterpart Amphibdelloides maccallumi to Torpedo nobiliana, but there is less correspondence between the attachment of Amphibdella torpedinis to Torpedo marmorata and that of Amphibdella flavolineata to Torpedo nobiliana. Although Amphibdella torpedinis attaches itself to the parietal mucosa rather than to the secondary 
TABLE 1. TAXONOMIC DESIGNATIONS, HOSTS, AND GEOGRAPHICAL SOURCES OF AMPHIBDELLID SPECIMENS STUDIED

Host

Torpedo nobiliana Bonaparte syn. Tetronarce occidentalis Storer syn. Tetranarce occidentalis Storer

Torpedo californica Ayres

Torpedo marmorata Risso

Torpedo torpedo (L.) syn. T. narke Risso

syn. $T$. ocellata Rudolphi

syn. Raja narce Nardo

Narcine brasiliensis (Olfers)
Author/

collector

Locality

Irish Sea

Irish Atlantic Slope

Sete, Mediterranean

Wood's Hole, U.S.A.

Plymouth

California

Sète, Mediterranean

Dr L. Euzet

Dr H. H. Williams

Dr L. Euzet

MacCallum (I9I6)

Llewellyn

\section{Alexander (I954)}

Genoa, Mediterranean Parona \& Perugia (I890)

Florida

Hargis (1955)

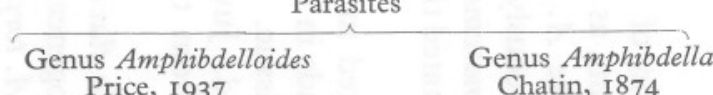

Amphibdelloides maccallumi

(Johnston \& Tiegs, 1922)

Price, 1937

syn. Amphibdella maccallumi

Johnston \& Tiegs, 1922

syn. 'Amphibdella torpedinis

Chatin' of MacCallum (1916)

Amphibdelloides maccallumi

(Johnston \& Tiegs, I922)

Amphibdelloides vallei sp.nov,

syn. 'Amphibdelloides mac-

callumi' of Euzet (I957) in

part

syn. 'Amphibdella torpedinis'

of Perugia \& Parona (I889)

= Valle's specimens from

Trieste

Amphibdella flavolineata

MacCallum, I916

Amphibdella torpedinis

Chatin, I874

Amphibdella parona perugiae sp.nov. syn.

'Amphibdella torpedinis

Chatin' of Parona \&

Perugia (I890) and

Ruszkowski (I93I) 
lamellae, it may be found not only on the proximal region of the primary lamella (P1. I, fig. 4B), i.e. near to the interbranchial septum, as in A. flavolineata, but on the distal region as well (Pl. I, fig. 4A); like A. flavolineata, A. torpedinis buries the posterior end of its body subcutaneously in its host.

I have not seen attached specimens of Amphibdelloides narcine or Amphibdella paronaperugiae, but Parona \& Perugia (I890, p. 364) stated that the latter species was attached to the 'mucosa parietale'.

The three juvenile specimens of $A$. flavolineata collected in the present study were all found among the loosely woven muscle strands in the ventricle of the heart, and did not appear to be attached to the host tissue. Other parts of the blood system of Torpedo nobiliana were not searched. Juvenile specimens of Amphibdella torpedinis were collected for me from the heart of Torpedo marmorata by Dr Louis Euzet.

The micro-habitat of juvenile specimens of Amphibdella flavolineata and $A$. torpedinis thus differs from that of any other known monogenean, excepting Ruszkowski's (1931) specimens of $A$. paronaperugiae (syn. A torpedinis) from the blood system of Torpedo torpedo. By far the greater number of monogeneans are ectoparasitic, but a few are endoparasitic in the coelom, oviducts, ureters, or urinary bladders of their hosts (see Llewellyn, 1957). The invasion of the blood system of an elasmobranch by a monogenean is not likely to have incurred undue physiological problems : food and oxygen supplies would change but little, and the osmotic relations with the ambient medium would also be relatively unchanged, since elasmobranchs are known to be approximately isosmotic with sea water (Smith, 1936). Probably the greatest novelty was the assumption of a tolerance of the high urea concentrations known to be present in elasmobranchs (Smith, 1936). The egg capsules could be released when the anterior end of the parasite emerges through the gill tissues to take up the definitive adhesive attitude illustrated for Amphibdella flavolineata in Pl. II, fig. 2.

\section{ATTACHMENT TO THE HOST}

The haptor of amphibdellids may contain three kinds of adhesive apparatus: 'hooklets' ( $=$ persistent oncomiracidial hooks) borne on papillae; large hooks, with or without an accessory sclerite ( = 'transverse bar'); and glands.

\section{Hooklet-bearing papillae}

Along the lateral margins of the haptor of Amphibdelloides maccallumi are borne, on each side, six very labile muscular papillae (Text-fig. I); five of these are truly marginal, but the remaining one is submarginal on the ventral surface immediately medial to the interval between the 3 rd and 4 th marginal papillae from the anterior end. In addition to these six pairs of papillae, two other pairs are present: first, a median pair on the posterior margin of the haptor, separated by a relatively wide interval from the remaining marginal 
(lateral) papillae, and secondly, a median pair on the ventral surface of the body immediately posterior to the transverse bar of the main hook-apparatus (see below). Each of the sixteen papillae bears an apical hooklet of about 6-8 $\mu$ long. These papillae are often obliterated if the usual practice is followed of flattening specimens before mounting them; the papillae are best seen in living specimens or in specimens relaxed in propylene phenexetol.

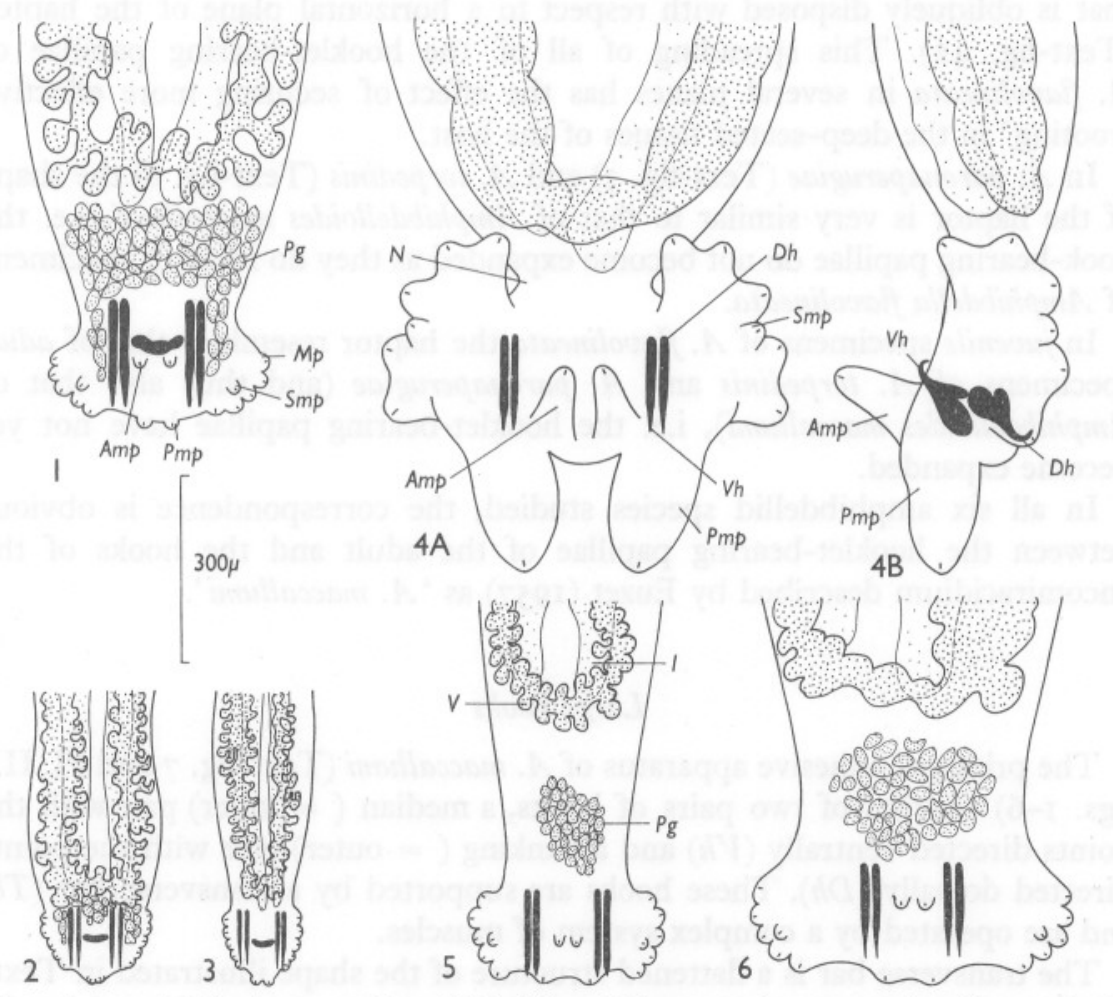

Text-figs. I-6. The haptors of amphibdellids, all drawn to the same scale. Fig. I. Amphibdelloides maccallumi. Fig. 2. A. vallei. Fig. 3. A. narcine. Figs. 4A, B. Amphibdella flavolineata, 4A ventral view, 4B side view. Fig. 5. A. paronaperugiae. Fig. 6. A. torpedinis. Amp, anterior median papilla; $D h$, dorsal hook; $I$, intestine; $M p$, marginal papilla; $N$, neck; $P g$, posterior gland; $P m p$, posterior median papilla; $S m p$, submarginal papilla; $V$, vitellarium; $V h$, ventral hook.

In $A$. vallei (Text-fig. 2) and $A$. narcine (Text-fig. 3 ) the haptor is less expanded laterally than in $A$. maccallumi, and in dorsal or ventral view is approximately triangular with the apex directed posteriorly. Suitably treated material for a detailed study of the distribution of the papillae in these two species was not available.

In Amphibdella flavolineata (Text-figs. 4A, B) there is a very well-marked neck region separating the haptor from the body-proper, the narrowness of 
the neck being emphasized by the great expansion of the haptor in the subcutaneous tissues of the host (P1. II, fig. 2). The two median pairs of papillae are very much larger than the lateral marginal ones: the posterior median papillae are greatly extended in a posterior direction (Text-fig. 4A) and the anterior median papillae are greatly extended in a ventral direction (Textfig. 4B). The lateral papillae are borne on a considerably expanded flange that is obliquely disposed with respect to a horizontal plane of the haptor (Text-fig. 4B). This spreading of all of the hooklet-bearing papillae of A. flavolineata in several planes has the effect of securing more effective 'rooting' in the deep-seated tissues of the host.

In $A$. paronaperugiae (Text-fig. 5) and $A$. torpedinis (Text-fig. 6 ) the shape of the haptor is very similar to that of Amphibdelloides maccallumi, i.e. the hook-bearing papillae do not become expanded as they do in adult specimens of Amphibdella flavolineata.

In juvenile specimens of $A$. flavolineata the haptor resembles that of adult specimens of $A$. torpedinis and $A$. paronaperugiae (and thus also that of Amphibdelloides maccallumi), i.e. the hooklet-bearing papillae have not yet become expanded.

In all six amphibdellid species studied, the correspondence is obvious between the hooklet-bearing papillae of the adult and the hooks of the oncomiracidium described by Euzet (I957) as 'A. maccallumi'.

\section{Large hooks}

The principal adhesive apparatus of $A$. maccallumi (Text-fig. 7 and Pl. III, figs. I-6) consists of two pairs of hooks, a median ( = inner) pair with the points directed ventrally $(V h)$ and a flanking ( = outer) pair with the points directed dorsally $(D h)$. These hooks are supported by a transverse bar $(T b)$ and are operated by a complex system of muscles.

The transverse bar is a flattened structure of the shape illustrated in Textfigs. 7 and $8 \mathrm{c}$, i.e. it consists of a median region and two antero-laterally inclined lateral regions. This bar lies transversely in the ventral region of the body at a position approximately midway along the length of the hooks. It is suspended from the integument of the body by two antagonistic systems of fibres: one set $(V f)$ joins the lateral regions of the bar directly to the integument of the ventral surface of the body, and the other, more powerful set $(P d f)$ curves dorsally and then posteriorly from the anterior surface of the transverse bar to the integument of the dorsal and posterior regions of the haptor.

It is not known whether these fibres are contractile, but their function appears to be that of anchoring the transverse bar firmly to the integument. It will be shown later than when the main hook-operating muscles contract there would be a tendency for the hooks to be drawn forwards in the body were 
they not attached to a bar which is itself tethered to resist a pull in this direction.

The hooks are of the form illustrated in Text-figs. $8 \mathrm{~A}$ and B. There is a slight but characteristic dissimilarity between the ventral and dorsal hooks, the former being the larger, especially in the 'shoulder' region. The distal curved regions of all four hooks are strongly birefringent, but the proximal

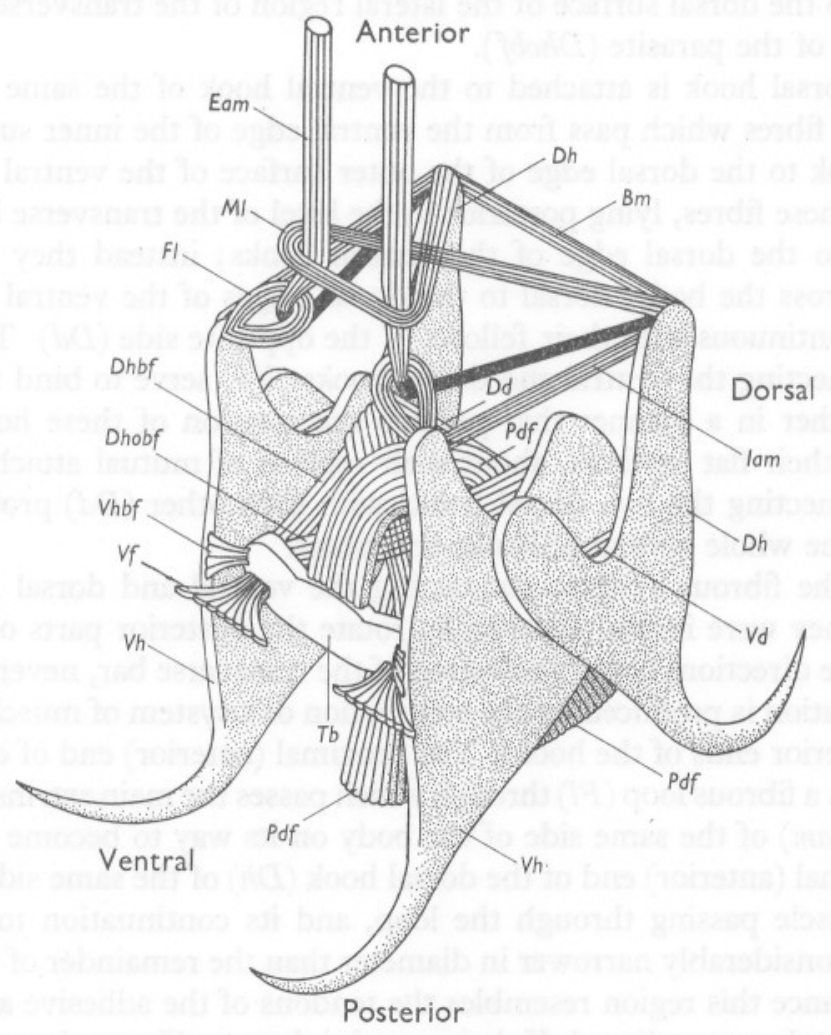

Text-fig. 7. The principal adhesive apparatus of Amphibdelloides maccallumi.

For explanation of lettering see text pp. 566-9.

blade-like regions much less so. All parts of the hooks may be differentially stained with malachite green, and, less readily so, with haematoxylin. Such is the affinity of the strongly birefringent regions for picric acid that, following fixation in Bouin's fluid, they remain yellow even after prolonged immersion in alcohol, and subsequent staining with haematoxylin is inhibited. At the place where the tip of each hook leaves the body it is surrounded by a muscular sheath (Pl. III, fig. I, Ms) which, in living specimens forcibly detached from the host, has been seen to oscillate rhythmically along the length of the basal region of the curved portion. 
Each ventral hook is attached to the transverse bar by three bundles of fibres: short fibres from the ventral edge of the hook to the adjacent lateral ends of the transverse bar $(V h b f)$; long fibres from the dorsal region of the inner ( = medial) surface of the hook to the lateral end of the transverse bar on the same side of the parasite $(D h b f)$; and long fibres from the same region of the hook (i.e. the dorsal region of the inner surface) obliquely ventrolaterally to the dorsal surface of the lateral region of the transverse bar on the other side of the parasite (Dhobf).

Each dorsal hook is attached to the ventral hook of the same side of the animal by fibres which pass from the ventral edge of the inner surface of the dorsal hook to the dorsal edge of the outer surface of the ventral hook $(V d)$. Some of these fibres, lying posterior to the level of the transverse bar, are not attached to the dorsal edge of the ventral hooks; instead they pass transversely across the body, dorsal to the dorsal edges of the ventral hooks, and become continuous with their fellows of the opposite side $(D d)$. Those fibres inter-connecting the ventral and dorsal hooks $(V d)$ serve to bind these hooks to each other in a manner that permits the rotation of these hooks, in the planes of their flat surfaces, about their regions of mutual attachment. The fibres connecting the two dorsal hooks with each other $(D d)$ probably serve to brace the whole system of hooks and fibres.

While the fibrous systems connecting the ventral and dorsal hooks $(V d)$ could, if they were indeed contractile, rotate the posterior parts of the hooks in opposite directions about the region of the transverse bar, nevertheless, the main actuation is produced by the contraction of a system of muscles attached to the anterior ends of the hooks. The proximal (anterior) end of each ventral hook bears a fibrous loop $(F l)$ through which passes the main extrinsic adductor muscle (Eam) of the same side of the body on its way to become attached to the proximal (anterior) end of the dorsal hook $(D h)$ of the same side. The part of the muscle passing through the loop, and its continuation to the dorsal hook are considerably narrower in diameter than the remainder of the muscle. In appearance this region resembles the tendons of the adhesive apparatus of Plectanocotyle gurnardi and Kuhnia scombri, but, unlike such tendons, they take up haematoxylin and xylidine ponceau and not light green in Masson's trichrome stain.

Since the hooks are pivoted about the transverse bar, contraction of the extrinsic adductor muscles (Eam) would draw the proximal ends of the dorsal and ventral hooks towards each other, and so cause the distal tips of the ventral hooks to rotate ventrally, and the distal tips of the dorsal hooks to rotate dorsally. When the parasite is located between successive secondary gill lamellae, such movements would result in the hooks impaling these lamellae and so securing the parasite to its host (Pl. II, fig. I).

The action of the main extrinsic adductor muscles is augmented by the contraction of smaller intrinsic adductor muscles (Iam) connecting directly 
with one another the proximal ends of the dorsal and ventral hooks on the same side of the body. The proximal ends of the dorsal hooks are connected to each other by a bracing muscle $(\mathrm{Bm})$.

From the proximal end of each of the dorsal hooks a muscle passes ventrolaterally towards the other side of the body, crosses its fellow from the other side, and then contributes to the formation of a single median loop $(M l)$ that surrounds the two extrinsic adductor muscles at a position immediately anterior to where these muscles become narrower before being threaded through the fibrous loops on the proximal ends of the ventral hooks. The function of this median loop is not obvious, but two possibilities are suggested: first, it could serve as a brace for the ventral components of the extrinsic adductor system; secondly, a tonic contraction of this loop about the narrow parts of the extrinsic adductor muscles would simulate a 'catch' mechanism and so relieve these muscles of the burden of continuous contraction; the relaxation of these adductor muscles (which stretch anteriorly more than half way along the animal) would permit exploratory movements of the body proper to be made more freely.

The hooks (and transverse bar when present) in the different species of amphibdellids exhibit characteristic variations in shape and size as indicated in Text-figs. 8-I3. It is to be noted that in Amphibdella paronaperugiae (Textfigs. I $3 \mathrm{~A}, \mathrm{~B})$ there is a distinct shoulder at the junction of the flattened blade with the slender curved part of the hook. This shoulder was found to be present in all four hooks of each of ten specimens from Torpedo torpedo examined, as, indeed, had been illustrated previously by Ruszkowski (I93I) in amphibdellid parasites from the same host species. In a similar sample of ten specimens of Amphibdella torpedinis from Torpedo marmorata no corresponding shoulder was found, but Chatin (1874) had illustrated a shoulder region in the hooks of his Amphibdella torpedinis specimens which were said to have been collected from the same host species. The absence of a shoulder region in the hooks was used by Price (1937) as the principal distinction between $A$. flavolineata MacCallum, I9I6 and Chatin's $A$. torpedinis. The evidence from the present study of amphibdellids suggests very strongly that either Chatin's drawing of the hooks, or his identification of the host, was inaccurate. Since the remainder of Chatin's description of $A$. torpedinis would be grossly inaccurate for any amphibdellid, it is proposed here to disregard his description of the shape of the hook, and to accept his identification of the host.

The muscles associated with the hooks and transverse bar in Amphibdelloides vallei and $A$. narcine are arranged exactly as those in A. maccallumi described above. In Amphibdella flavolineata, A. torpedinis, and A. paronaperugiae there is no transverse bar, and the fibres associated with such a bar in Amphibdelloides are absent. In Amphibdella torpedinis and A. paronaperugiae the adductor muscle system differs from that of Amphibdelloides 
maccallumi in that no median loop ( $M l$ in Text-fig. 7$)$ is present, but the 'bracing muscle' ( $B m$ in Text-fig. 7) is relatively much better developed. The hook muscles in Amphibdella flavolineata are arranged completely differently from those of the other five amphibdellid species studied: there are no fibrous loops on the proximal ends of the ventral hooks ( $F l$ in Text-fig. 7), there is

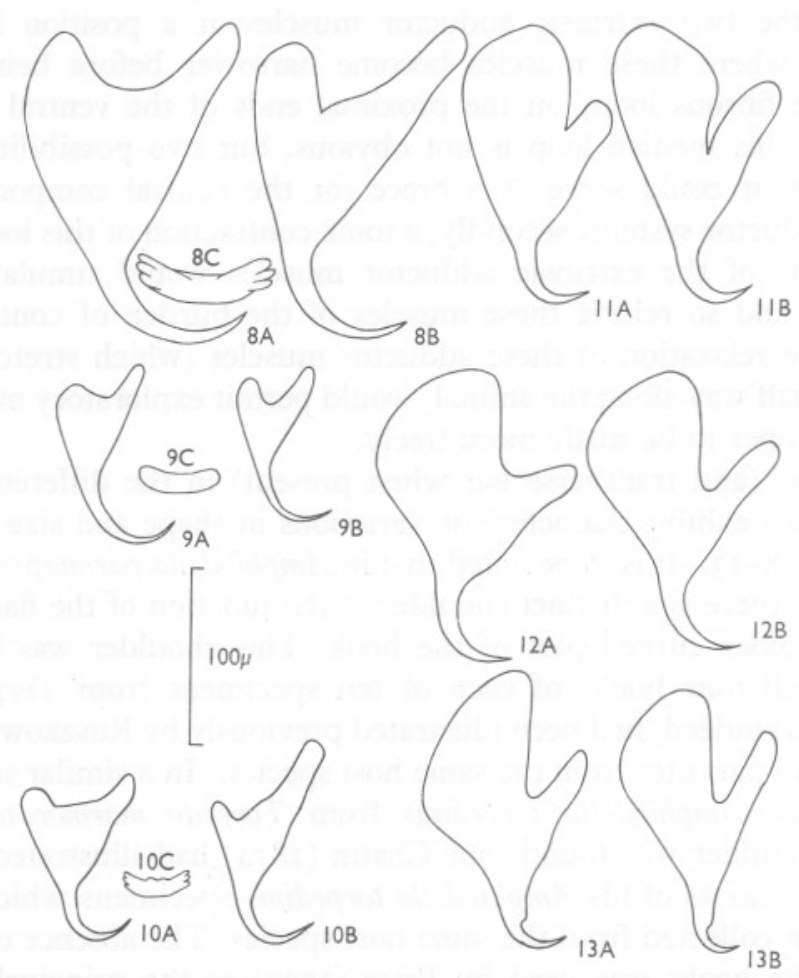

Text-figs. 8-I3. The hooks and supporting bars of amphibdellids, all drawn to the same scale. A, ventral hooks; B, dorsal hooks, C, supporting bars. Figs. 8A, B. c. Amphibdelloides maccallumi. Figs. 9A, B, c. A. vallei. Figs. IOA, B, C. A narcine. Figs. I I A, B. Amphibdella flavolineata. Figs. I2A, B. A. torpedinis. Figs. I3A, B. A. paronaperugiae. (Figs. IOA, B after Hargis, 1955.)

no 'median loop' ( $M l$ in Text-fig. 7) and there are no muscles connecting the hooks of the left side of the parasite with those of the right. The muscles that are present consist of simple longitudinally running bundles, one relatively weak bundle from each hook going posteriorly to the integument between the posterior median hooklet-bearing lobes, and much better developed bundles on each side running anteriorly to beyond the neck region of the haptor. 


\section{Posterior glands}

At the posterior end of the body of Amphibdelloides maccallumi, between the posterior regions of the vitellaria and the hooks of the adhesive apparatus, is a prominent mass of gland cells (Text-fig. I). Posteriorly some extensions from the gland flank the large hooks of the adhesive apparatus and probably lead one to each of the two posterior median hooklet-bearing lobes.

There is no trace whatsoever, in whole specimens or in sections, of a corresponding gland in either juveniles or adults of Amphibdella flavolineata, but well-developed glands are present in A. torpedinis and A.paronaperugiae. A prominent posterior gland is also present in Amphibdelloides vallei but Hargis (1955) did not report a posterior gland in $A$. narcine, nor have I been able to find one in Hargis's specimens.

The gland cells have coarsely granular contents that readily take up carmine stains and acid dyes such as light green, aniline blue, and xylidine ponceau; they give a strongly positive result when treated with the periodic acid-Schiff test for polysaccharides. Because of its topographical situation, the gland appears likely to play a part in the attachment of the parasite to its host. If this be so, the secretion of the gland might either histolyse the host tissues or act as a cement. However, in sections of $A$. maccallumi attached to Torpedo nobiliana (P1. II, fig. I) the host epidermis, though stretched and compressed, showed no signs of erosion apart from the perforations made by the large hooks themselves; nor was any cement substance to be seen between the parasite and host tissues though such cement, if present in living parasites, could of course have been removed by histological processing.

\section{ANTERIOR GLANDS}

At the anterior end of Amphibdelloides maccallumi, and opening on to the three pairs of papillae on the anterio-lateral borders of the parasite, are some well defined anterior glands (Text-fig. I4). Their function is not known, but presumably it is either adhesive (to keep the mouth in a feeding position) or histolytic (to soften host tissues to permit ingestion).

Exactly similarly disposed glands are present in $A$. vallei and $A$. narcine, but in all three species of Amphibdella, namely, A. flavolineata, A. torpedinis, and $A$. paronaperugiae, there are no papillae and the openings of the ducts of the glands nearly always converge to form a single mass on each side of the body (Text-fig. I5). In a sample of ten balsam-mounted preparations of $A$. flavolineata a subdivision into three tracts of ducts could be recognized on one side only of each of two specimens, and in one living specimen examined especially for this character, there was no trace of subdivision within the paired masses of anterior glands. The same situation occurs in A. torpedinis, but I have found no evidence of any subdivision at all in the paired anterior 
glands of $A$. paronaperugiae. Ruszkowski (I93I, fig. I) illustrated a single mass of 'cephalic glands' in parasites from Torpedo torpedo which he called Amphibdella torpedinis but which the present study shows to belong to the new species $A$. paronaperugiae.

\section{GENITALIA \\ Male (Text-figs. I4-22)}

In all of the six species of amphibdellid studied there is a single testis $(T)$ lying between the two intestinal limbs in the mid-dorsal region of the body, and extending posteriorly almost to the posterior ends of these intestinal limbs. Anteriorly the testis gives rise to the vas deferens $(V d)$ which passes obliquely forwards, towards the animal's left, to the posterior end of the vesicula seminalis $(V s)$. In Amphibdelloides the undifferentiated vas deferens enters the vesicula seminalis directly, but in Amphibdella a well developed and characteristic dilatation of the vas deferens $(D v d)$ is present immediately posterior to the vesicula seminalis.

The vesicula seminalis is a prominent organ with walls provided with well developed longitudinal and transverse muscle fibres that may be seen especially easily in living specimens examined in polarized light. The vesicula seminalis passes obliquely forwards from the animal's left towards the right, and at its anterior end gives off a sperm duct $(S d)$ which passes towards the left. This sperm duct then receives two ducts, one from each of the two prominent 'prostate' reservoirs (Prr) and the union of all three ducts has common and direct access to the slightly expanded base of the sclerotized penis which curves away anteriorly. Each prostate reservoir is connected by a short and very narrow duct $(2-3 \mu$ in diameter) with a relatively large 'prostate' gland (Prg). The disposition of the two prostate reservoirs (which, in whole specimens, are much more prominent than their associated glands), one anterior and the other posterior to the junction of the sperm duct with the penis, is characteristic of the family.

The copulatory apparatus consists of a very long slender sclerotized penis accompanied by a pair of relatively very large robust accessory sclerites which resemble somewhat a pair of pincers. This apparatus lies in the sagittal plane of the parasite with its proximal, posterior end lying dorsally in the body and with its long axis sloping anteriorly and ventrally so that the penis emerges on the ventral surface of the body. Its detailed structure may be seen only in well-flattened and consequently distorted specimens, and is best studied when dissected from fresh or partly decomposed specimens.

In both Amphibdella and Amphibdelloides (Text-figs. I6-2I) there is a single-pointed strongly curved hook-like accessory sclerite on the parasite's left, and a differently shaped accessory sclerite on the right. In Amphibdella this right sclerite is a tube with an open trumpet-shaped distal end, but in 
Amphibdelloides it is a hook. In A. maccallumi this hook bears five prongs lying in different planes so that it is only rarely that all five may be seen in one specimen. While the function of the combined pair of accessory sclerites is probably identical in Amphibdella and Amphibdelloides, namely, to act as a
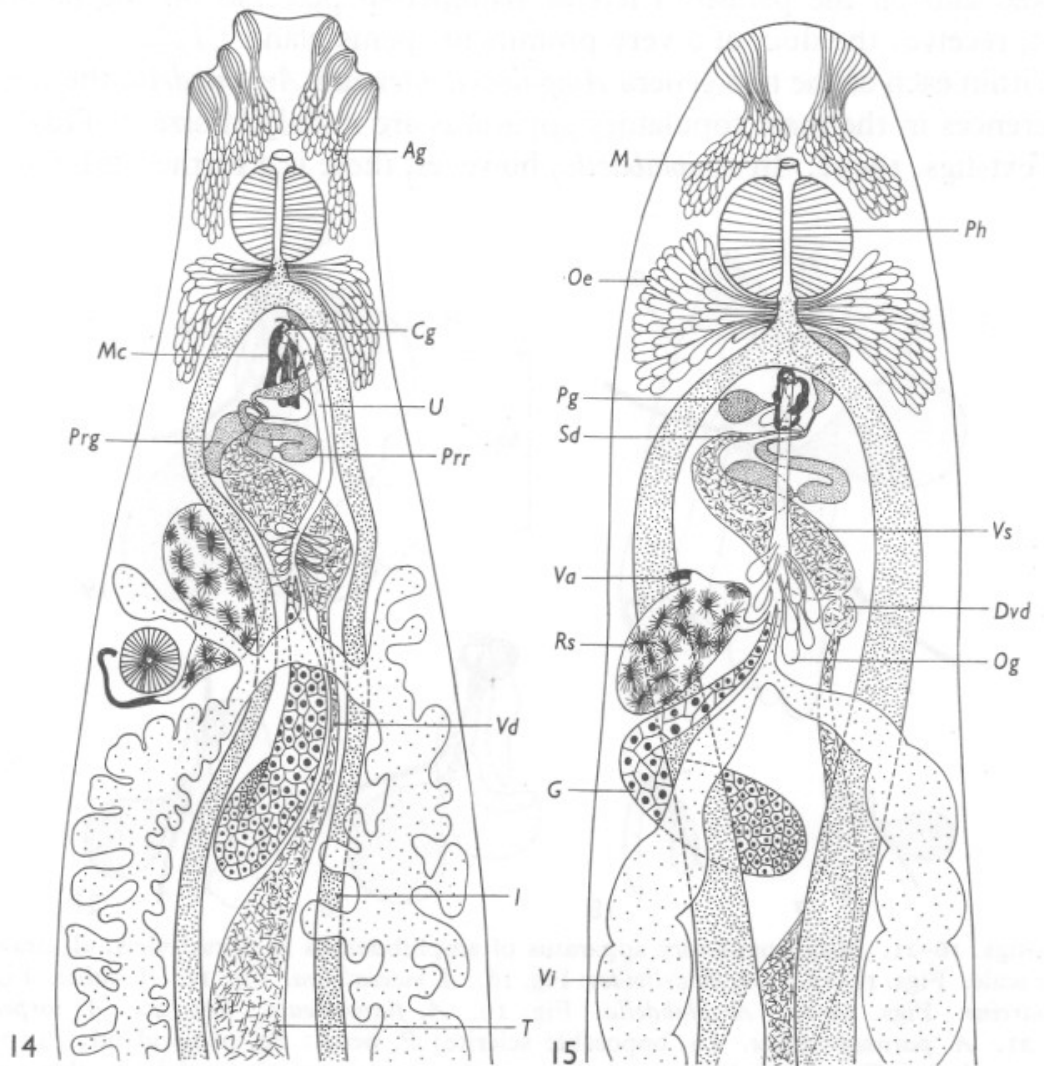

Text-figs. I4, I5. Genitalia and anterior glands of amphibdellids. Fig. I4. Amphibdelloides maccallumi. Fig. I5. Amphibdella flavolineata. Ag, anterior gland; $\mathrm{Cg}$, common genital opening; $D v d$, dilatation of vas deferens; $I$, intestine; $G$, germarium; $M$, mouth; $M c$, male copulatory apparatus; Oe, oesophageal glands; $\mathrm{Og}$, ootype glands; $\mathrm{Pg}$, penis gland; $\mathrm{Ph}$, pharynx; Prg, 'prostate' gland; Prr, 'prostate' reservoir; Rs, receptaculum seminis; $S d$, sperm duct; $U$, uterus; $V a$, vagina; $V d$, vas deferens; $V i$, vitellarium; $V s$, vesicula seminalis; $T$, testis.

pair of pincers to grasp the vaginal region of the co-copulant and so to facilitate the insertion of the slender penis, nevertheless, there is a great difference in the division of labour between the two members of the pair of accessory sclerites in the two genera. In Amphibdelloides the single-hooked sclerite of the left $(P s)$ is perforated to carry the penis, with the hook of the right serving as the opposable pincer $(O s)$, whereas in Amphibdella it is the trumpet-like 
sclerite of the right side which acts as the penis-bearer $(P s)$ and the singlehooked sclerite of the left as the opposable sclerite $(O s)$.

At the point of entry of the penis into the penis-bearing sclerite, this sclerite in all species of both genera (excepting Amphibdelloides narcine) whether it be hooked and on the parasite's left or trumpet-shaped and on the parasite's right, receives the duct of a very prominent 'penis gland' $(\mathrm{Pg})$.

Within each of the two genera Amphibdelloides and Amphibdella the specific differences in the male copulatory apparatus are mainly of size, as illustrated in Text-figs. I6-2I. In Amphibdella, however, there is a further difference in
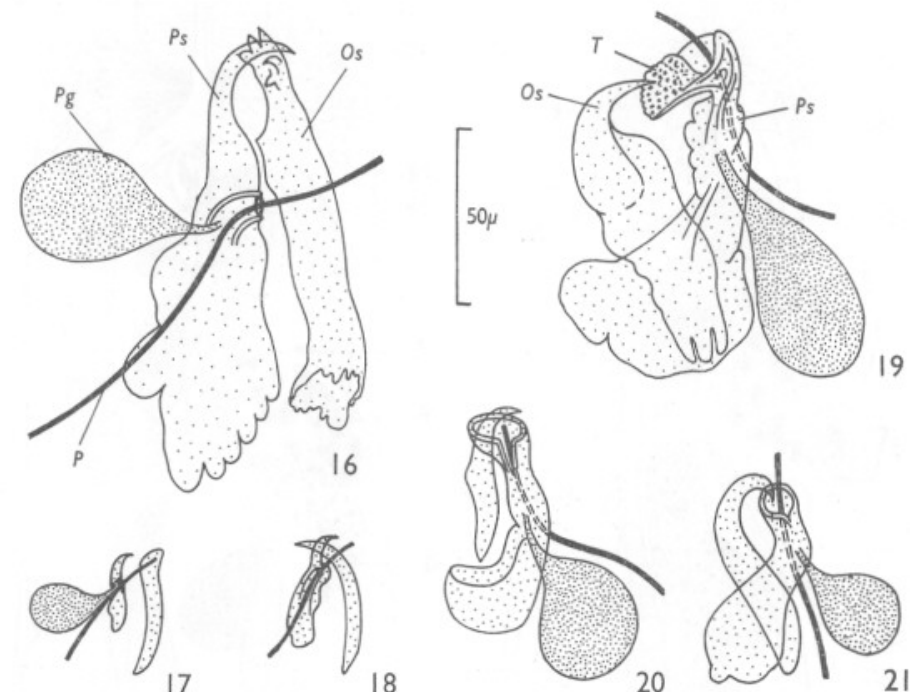

Text-figs. I6-21. Male copulatory apparatus of amphibdellids in dorsal view, all drawn to same scale. Figs. 16-18. Amphibdelloides: Fig. 16. A. maccallumi. Fig. 17. A. vallei. Fig. I8. A. narcine. Figs. 19-21. Amphibdella. Fig. 19. A. flavolineata. Fig. 20. A. torpedinis. Fig. 2r. A paronaperugiae. $O s$, opposable sclerite; $P$, penis; $P g$, penis gland; $P s$, penisbearing sclerite; $T$, tubercled lip region of penis-bearing sclerite of Amphibdella flavolineata.

that while the distal end of the penis-bearing sclerite of $A$. flavolineata has a prominent tubercled 'lower-lip' region ( $T$ in Text-fig. I9), such a feature is absent from A. torpedinis (Text-fig. 20) and A. paronaperugiae (Text-fig. 2I). In Amphibdelloides narcine, Hargis (1955) did not report, nor have I been able to find, a penis gland. Again in $A$. narcine the accessory sclerites were described by Hargis as being only $18-3 \mathrm{I} \mu$ in length, but in well-flattened specimens, or in specimens in which the copulatory sclerites can be seen in side view, I have found the opposable sclerite to be $37(36-40) \mu$ long.

The copulatory apparatus of amphibdellids is provided with various muscles, the most prominent of which are indicated in Text-fig. 22, which was constructed from observations of whole mount specimens of A. maccallumi 
seen in polarized light. Smaller muscles, which appear to be antagonists to some of the larger ones included in Text-fig. 22, are also present, but they have been omitted from the diagram to reduce confusion. A special hazard in the determination of the distribution of the muscles of the copulatory

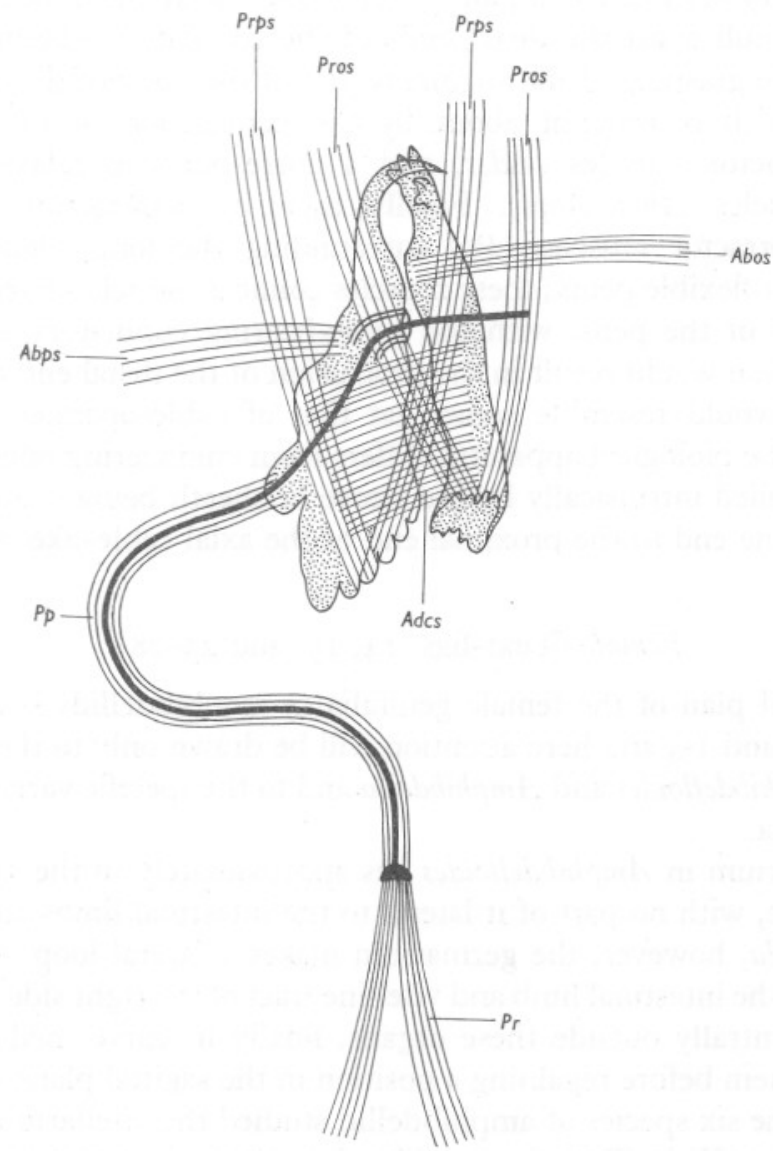

Text-fig. 22. The male copulatory apparatus of Amphibdelloides maccallumi, accessory sclerites somewhat displaced to permit illustration of muscles. Abos, abductor of opposable sclerite; $A b p s$, abductor of penis-bearing sclerite; $A d c s$, adductor of copulatory sclerites; $P p$, protractors of penis; Pr, retractors of penis; Pros, protractors of opposable sclerite; Prps, protractors of penis-bearing sclerite.

apparatus was the presence of sphincter muscles (not shown in Text-fig. 22) surrounding the opening of the genital atrium and lying immediately ventral to the distal ends of the copulatory sclerites.

The copulatory apparatus has not been seen working, but from a consideration of the spatial relationships between the various parts in $\mathrm{A}$. mac- 
callumi it seems likely that its mode of action is as follows. With the distal end of the penis still contained within the penis-bearing sclerite, the distal ends of the two copulatory sclerites are extruded through the opening of the common genital atrium by the contraction of the protractor muscles, of which each copulatory sclerite has a pair (Pros, Prps). Next the abductor muscles (Abos, Abps) pull apart the distal ends of the copulatory sclerites as a preliminary to the grasping of the vaginal region of the body of the co-copulant, an action which is brought about by the contraction of the proximally situated adductor muscles $(A d c s)$ and a corresponding relaxation of the abductor muscles (Abos, $A b p s$ ). Finally; there is a contraction of the loose sleeve of protractor muscles $(P p)$ surrounding the long, slender, curved sclerotized but flexible penis; these muscles connect the sclerotized disc at the proximal end of the penis with the penis-bearing copulatory sclerite, and their contraction would result in the protrusion of the distal end of the penis. Such action would resemble somewhat that of cable-operated mechanical devices, but the biological apparatus differs from engineering ones in that the power is supplied intrinsically by the sleeve or sheath being itself contractile and fixed at one end to the proximal end of the axial cable-like penis.

\section{Female (Text-figs. I4, 15, and 23-28)}

The general plan of the female genitalia in amphibdellids is as shown in Text-figs. I4 and 15, and here attention will be drawn only to the differences between Amphibdelloides and Amphibdella and to the specific variations within the two genera.

The germarium in Amphibdelloides lies approximately in the sagittal plane of the parasite, with no part of it lateral to the intestinal limbs and vitellaria. In Amphibdella, however, the germarium makes a lateral loop which passes first dorsal to the intestinal limb and vitelline tract of the right side of the body, then turns ventrally outside these organs, finally to curve medially to pass ventrally to them before regaining a position in the sagittal plane of the body.

In five of the six species of amphibdellid studied the vitellarium was found to be follicular ( $V i$ in Text-fig. I4) like that of the vast majority of monogeneans, but in $A$. flavolineata the vitellarium was found to consist of two long tubes exhibiting only a very slight degree of lobing. Paraffin sections of A flavolineata showed no trace of a follicular organization inside the vitellarium.

In Amphibdelloides the vagina opens on the dorso-lateral surface of the body, but in Amphibdella it opens on the ventro-lateral surface. Within each of the two genera, the main variations in the female genitalia are as follows: differences in the length of the sclerotized vagina; variations in the site of origin of the vagina from the receptaculum seminis; differences in the form of the distal end of the vagina, whether a simple tube or whether provided with an 
expanded sclerite; the presence or otherwise, and the degree of development of, a vaginal gland; and the size, and sometimes the shape, of the receptaculum seminis. With regard to the last character, it must be pointed out that in most species the receptaculum seminis in life is probably spherical, but that it suffers considerable change when specimens are flattened. In Amphibdelloides maccallumi, however, the receptaculum seminis is characteristically pyriform with the narrow end directed posteriorly. Moreover, a special organ ('fibrous pad') is present in this species, and will be described below. The particular form of the female copulatory apparatus in the various amphibdellids is illustrated in Text-figs. 22-28, and will be referred to in the specific diagnoses on pp. 580-2.
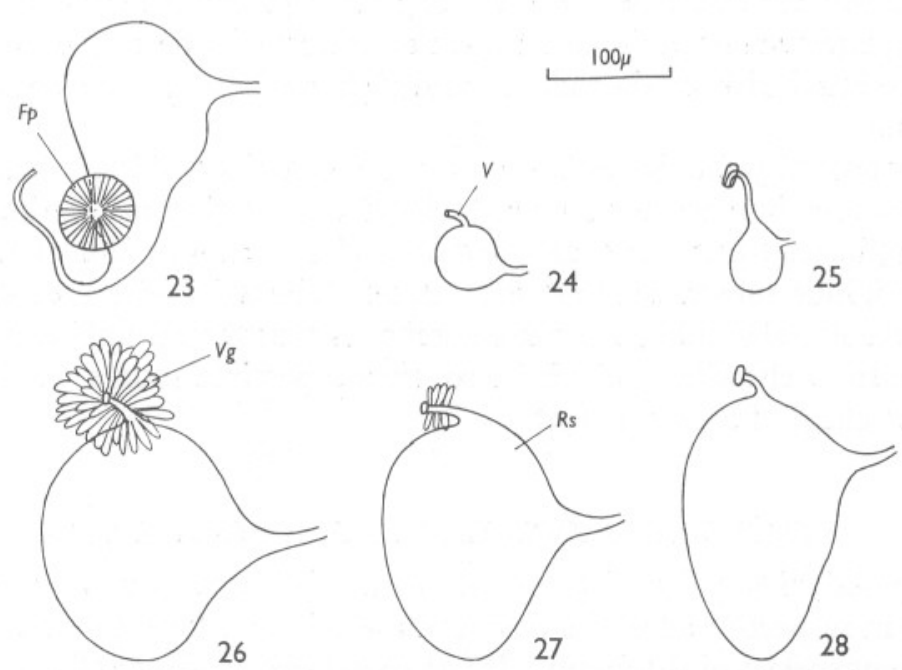

Text-figs. 23-28. Female copulatory apparatus of amphibdellids in dorsal view, all drawn to same scale. Figs. 23-25. Amphibdelloides. Fig. 23. A. maccallumi. Fig. 24. A. vallei. Fig. 25. A. narcine. Figs. 26-28. Amphibdella. Fig. 26. A. flavolineata. Fig. $27 . A$. torpedinis. Fig. 28. A. paronaperugiae. $F p$, fibrous pad; $R s$, receptaculum seminis; $V$, vagina; $V g$, vaginal gland.

Near to the vaginal opening in A. maccallumi there is a thick disc of fibrous tissue simulating somewhat the appearance of a sucker (Text-figs. I4, 23). In this disc the fibres are arranged perpendicularly to the body surface of the parasite, but they are not bounded from the underlying tissue by a basement membrane. Moreover, there appears to be no trace of a concavity on the outer surface of the organ such as is present in ordinary acetabulate suckers. It is necessary to point out too that this fibrous disc lies to one side of (and so does not surround) the vaginal opening as it was described to do so by Alexander (1954) in A. maccallumi from Torpedo californica. The fibrous disc is not easily seen in whole specimens except when observed by phase contrast 
microscopy, but it is readily seen in sections (Pl. II, fig. I on the dorsal surface of the parasite, one-quarter of the length of the animal from the anterior end). Dr Alexander was kind enough to lend me some of his specimens of $A$. maccallumi from Torpedo californica, and I have confirmed that the position of the fibrous disc in these specimens is the same as in Plymouth specimens of Amphibdelloides maccallumi. There is no trace of a corresponding organ in the other amphibdellids studied.

If the fibrous disc is in fact a sucker, then its special function would appear to be that of attaching the vaginal region of the parasite to the genital atrial region (i.e. the region of the extruded accessory copulatory sclerites) of the co-copulant. But if the organ is not a sucker, as indeed seems the more likely, then it is possible that it serves as a 'toughened pad' which may be gripped firmly by, and even be perforated by, the accessory sclerites of the co-copulant with a reduced risk of damage to underlying organs such as the gut or vitellarium.

It is noteworthy that in both Amphibdelloides and Amphibdella the sperms in the receptaculum are not randomly distributed as they are in the vesicula seminalis; instead they are aggregated around spherical or elongated masses of an acidiphilic substance (Text-figs. I4, I5). The walls of the receptaculum seminis are not glandular, and the inference is that the acidiphilic substance has come from elsewhere; if this be so, then a possible source would be the 'prostate' gland of a co-copulant.

\section{STATUS OF BLOOD-LIVING AMPHIBDELLIDS}

The amphibdellids collected from the hearts of electric rays were examined carefully in respect of all of the characters which have been found to vary in the different species of the family. It was found that specimens from the heart of Torpedo nobiliana were very similar to specimens of Amphibdella flavolineata from the parietal mucosa of the gills of the same host, differing only in their smaller size, in the absence of enlarged hooklet-bearing lobes, in the absence of vitellaria, and in the presence of only a rudimentary germarium. The size and shape of the accessory sclerites of the male copulatory apparatus, including the tubercled trumpet-shaped opening of the penis-bearing sclerite, was identical in the blood stream and gill mucosa forms, as also were the position of the ventrally opening vagina anterior to the receptaculum seminis, the presence of a dilatation in the vas deferens immediately preceding the vesicula seminalis, the shape of the large hooks, and the absence of a transverse bar and a posterior gland.

An almost parallel situation was present in the amphibdellids from the heart of Torpedo marmorata, but here a rudimentary posterior gland was present, and the shape and size of the hooklet-bearing lobes of the haptor was as in Amphibdella torpedinis from the parietal mucosa of the gills. 
It is noteworthy that in the amphibdellids from the hearts of both Torpedo nobiliana and T. marmorata, while the female gonads were invariably undeveloped, in all specimens examined the vesicula seminalis was full of sperms showing that the testis was already functional. Moreover, the receptaculum seminis was invariably well filled with sperms, indicating that copulation had probably taken place.

The obvious inference is that these amphibdellids from the blood systems of their hosts are 'juvenile' specimens of the Amphibdella species which attaches itself to the gill mucosa of the particular host species. The blood parasites are juvenile in that the female genitalia are as yet immature, but the male genitalia are already mature. An alternative view would be to regard the blood-living parasites as protandrous adults.

The advantage of a protandrous stage living freely in the blood stream would be in the greatly improved opportunities for meeting a partner and so of permitting cross-fertilization to take place. Copulation between gill specimens permanently anchored in the subcutaneous tissues of the host would be restricted to those specimens happening to lie very near to each other. Such a distribution has been observed occasionally in A. torpedinis, but in none of the specimens of $A$. flavolineata that I have collected from the gills would copulation have been possible.

The life-cycle of species of the genus Amphibdella then would appear to be as follows. Free-living sixteen-hooked oncomiracidia encounter the appropriate torpedinid host and, instead of settling permanently on the superficial gill tissues as other monogenean gill parasites are thought to do, penetrate into the blood vessels of the gills. The larva is carried around in the blood stream and develops until eventually it exchanges sperms with a co-copulant. It would then emerge, anterior end first, through the gill mucosa (the parasite being too big to enter the capillaries of the secondary lamellae), thus exposing the uterine aperture for oviposition, and with the posterior end remaining within the host tissues. It seems unlikely that the parasite would emerge completely and then re-insert the posterior end of its body into the host, for there appears to be no boring apparatus present; 'posterior glands' of uncertain function are indeed present in $A$. torpedinis and $A$. paronaperugiae but are absent from $A$. flavolineata. Ruszkowski (193I) found egg-laying specimens and free egg capsules of $A$. paronaperugiae in the blood system of Torpedo torpedo; but he also reported (p. I63) individuals of the same species as living on the gills; it is possible that the egg-capsules in the blood system were merely an example of precocious egg-laying. 


\section{TAXONOMY}

The preceding comparisons of amphibdellids from various micro-habitats on various torpedinid host species have made necessary certain taxonomic revisions; these are given below.

\section{Family: AmPHIBDELlidAe Bychowsky, I957 emend.}

Tetraonchidea (Bychowsky, I957) with bifurcate but otherwise unbranched intestine; adults with two pairs of large hooks, with or without a single supporting bar; sixteen persistent oncomiracidial hooklets arranged as five lateral pairs including four marginal pairs and one submarginal pair, and two median pairs including one posterior terminal pair and one centrally placed pair; eyes absent in oncomiracidium and adult; adults parasitic on secondary gill lamellae or gill mucosa of Torpedinidae, but juveniles of some species endoparasitic in blood system of host. Type genus: Amphibdella Chatin, I874.

The above family diagnosis differs from that given by Bychowsky in that it recognizes that the supporting bar is absent from half of the known species, and in that it gives more details about the distribution of persistent oncomiracidial hooks in the adult, and about the micro-habitats of the parasites. Since the type genus is Amphibdella, the family name should be Amphibdellidae not 'Amphibdellatidae' as given by Bychowsky.

\section{Genus: Amphibdella Chatin, I874}

Amphibdellidae without transverse bar supporting the large hooks; posterior gland present or absent; germarium loops around right intestinal limb; vitellarium follicular or tubular; vaginal opening on ventro-lateral surface of body; with or without vaginal gland; vagina arising from anterior end of receptaculum seminis; with dilatation in vas deferens immediately preceding vesicula seminalis; right male copulatory sclerite trumpet-shaped and serving as penis-bearer, left male copulatory sclerite with terminal hook; adults parasitic on mucosa of gills, but some development, involving protandry, takes place in blood system of host. Type species: Amphibdella torpedinis Chatin, I874.

\section{Amphibdella torpedinis Chatin, 1874}

Length $4.45(3.20-5.68) \mathrm{mm}$, width $0.68(0.60-0.80) \mathrm{mm}$; haptor not separated from remainder of body by a narrow neck; hooklet-bearing lobes not greatly enlarged; large hooks $I_{55}\left(\mathrm{I}_{3} 6-\mathrm{I} 72\right) \mu$ long, of characteristic shape illustrated in Text-figs. I2A, B and lacking a distinct shoulder at the junction of the broad flattened part with the curved slender part; with posterior gland; penis-bearing copulatory sclerite 64 $(60-78) \mu$ long and with smooth trumpet; vaginal gland poorly developed; distal end of vagina slightly swollen to about 8-IO $\mu$ external diameter; parasites of gill mucosa of Torpedo marmorata with part of juvenile development in blood system of same host. 


\section{Amphibdella paronaperugiae sp.nov.}

Length $3.82(2.60-4.80) \mathrm{mm}$, width $0.37(0.24-0.46) \mathrm{mm}$; large hooks I38 (I32-I48) $\mu$ long, with distinct shoulder at junction of broad flattened part with curved slender part as illustrated in Text-figs. $13 \mathrm{~A}, \mathrm{~B}$; vaginal gland absent; distal end of vagina swollen to $\mathrm{I} 2-\mathrm{I} 6 \mu$ external diameter; penis-bearing copulatory sclerite $54(48-58) \mu$ long; parasites of gill mucosa of Torpedo torpedo, but some egg-laying adults, probably precociously developed, have been reported from the blood system of the host. Other characters as in Amphibdella torpedinis.

\section{Amphibdella flavolineata MacCallum, I9I6}

Length $4.85(3.20-6 \cdot 60) \mathrm{mm}$, width $0.75(0.40-\mathrm{I} \cdot 20) \mathrm{mm}$; haptor separated from remainder of body by a narrow neck; two median pairs of hooklet-bearing lobes greatly expanded; large hooks $\mathrm{I} 56(\mathrm{I} 52-160) \mu$ long and lacking distinct shoulder at junction of broad flattened part with curved slender part as illustrated in Text-figs. I I A, B; without posterior gland; vitellarium tubular and not follicular; penis-bearing copulatory sclerite IO2 (96-II6) $\mu$ long with tubercled lip to trumpet as illustrated in Text-fig. I9; with very well-developed vaginal gland; distal end of vagina only very slightly swollen to about 6-8 $\mu$ external diameter; parasites of gill mucosa of Torpedo nobiliana, with part of juvenile development in blood system of same host.

\section{Genus: Amphibdelloides Price, I937}

Amphibdellidae with transverse bar supporting the large hooks; posterior gland present; germarium lying entirely within the intercaecal field; vitellarium always follicular; vagina opening on dorso-lateral surface of the body; without vaginal gland; vagina arising from anterior or posterior end of receptaculum seminis; without dilatation in vas deferens; left copulatory sclerite hook-shaped and serving as penis-bearer, right copulatory sclerite another hook, sometimes with terminal prongs; adults parasitic on secondary gill lamellae of hosts, juvenile development not known. Type species: Amphibdelloides maccallumi (Johnston \& Tiegs, 1922) Price 1937.

\section{Amphibdelloides maccallumi (Johnston \& Tiegs, I922) Price, I937}

Length $2.66(2.00-3.00) \mathrm{mm}$, width $0.45(0.32-0.58) \mathrm{mm}$; large hooks I72 (I60-194) $\mu$ long, of characteristic shape illustrated in Text-figs. $8 \mathrm{~A}$, B and supported by a transverse bar $79(72-84) \mu$ long; with fibrous pad near vaginal aperture; vagina arising from posterior end of receptaculum seminis and ending in a simple tubular opening; receptaculum seminis pyriform with narrow end directed posteriorly; penis-bearing copulatory sclerite $\mathrm{I} 4 \mathrm{O}(\mathrm{I} 30-\mathrm{I} 60) \mu$ long; parasitic on Torpedo nobiliana and T. californica.

\section{Amphibdelloides vallei sp.nov.}

Length $0.86(0.60-\mathrm{I} \cdot 20) \mathrm{mm}$, width $0.14(0 \cdot 10-0.24) \mathrm{mm}$; large hooks $100(92-104)$ $\mu$ long, of characteristic shape illustrated in Text-figs. $9 \mathrm{~A}$, B and supported by a transverse bar $44(42-48) \mu$ long; without fibrous pad near vaginal opening; vagina arising from anterior end of receptaculum seminis and ending in a simple tubular opening; receptaculum seminis spherical; penis-bearing copulatory sclerite $37(35-38) \mu$ long; parasitic on Torpedo marmorata. 
Amphibdelloides narcine Hargis, 1955 (diagnosis based mainly on Hargis, 1955)

Length $0.90(0.79-1.87) \mathrm{mm}$, width $0.16(0.15-0.19) \mathrm{mm}$; large hooks 97 (85-108) $\mu$ long, of characteristic shape illustrated in Text-figs. IOA, B and supported by a transverse bar 35 (26-5I) $\mu$ long; without fibrous pad near vaginal opening; vagina arising from anterior end of receptaculum seminis and ending in a sclerotized plate about I8 (I6-20) $\mu$ long by Io (8-I2) $\mu$ wide (in the illustration of the sclerotized plate of the vagina by Hargis, 1955, fig. 18, the scale is erroneously magnified by a factor of about 5); receptaculum seminis slightly pyriform with narrow end directed anteriorly; penis-bearing copulatory sclerite $37(36-40) \mu$ long (see p. 574); parasitic on Narcine brasiliensis.

\section{Other species of the Amphibdellidae}

Both Monticelli (I890) and Ruszkowski (I93I, footnote to p. I64) have referred to what is likely to be a new species of Amphibdelloides from the secondary gill lamellae of Torpedo torpedo.

Bychowsky (1957) has referred to an amphibdellid from the gills of T. smithi from the Arabian Sea, Baluchistan.

I have had an opportunity of seeing a new species of Amphibdella from the gills of Narcine timlei from South India; this amphibdellid was found by and will be described by $\mathrm{Mr} \mathrm{R}$. V. Unnithan.

On the basis of the above classificatory scheme, it is now proposed to review the taxonomic histories of the various amphibdellid species.

The first monogenean from an electric ray was described by Chatin (I874) as Amphibdella torpedinis (without a transverse bar in the adhesive apparatus) and was collected from the gills of Torpedo marmorata at Naples. Chatin's description was vague and inaccurate, and a more detailed diagnosis of the species, based on specimens collected from the same host species at Sète (Mediterranean, Gulf of Lyons), is given in the present paper.

Monogeneans were also found on this same host T. marmorata at Trieste by Valle, who sent the parasites to Genoa, where they were described by Perugia and Parona (1890) under the name of 'Amphibdella torpedinis Chatin'. Valle's specimens were said to have one transverse bar in the adhesive apparatus, but in a later paper (Parona \& Perugia, I890) this observation was qualified: it was now stated that there were really two bars present, one of them having been omitted from the illustration in the earlier paper for the sake of simplicity. In describing two bars as being present, however, Parona \& Perugia were almost certainly mistaken: as pointed out by Bychowsky (I957), what was thought to be the second transverse bar was very probably the muscle connecting the anterior ends of one of the pairs of hooks. A corresponding muscle $(\mathrm{Bm})$ in Amphibdelloides maccallumi is illustrated in Text-fig. 7. This second amphibdellid (with one transverse bar) from Torpedo marmorata has been designated in the present study a new species Amphibdelloides vallei.

Following their description (written in November 1889) of Valle's amphibdellids from Torpedo marmorata, Parona and Perugia (I890) themselves 
collected and described in April 1890 some monogeneans from T. torpedo (syn. T. narce) at Genoa. These parasites were collected not from the gill lamellae, but from the parietal mucosa of the gill chamber, and were found to be without a transverse bar. Though Parona \& Perugia described the parasites from the parietal mucosa of T. torpedo as Amphibdella torpedinis Chatin, their specimens (from the C.E.C.I., Naples) have been re-examined in the course of the present study and were found to belong in fact to a new species (without bar) for which the name $A$. paronaperugiae has been proposed. The same species was collected from the gills of Torpedo torpedo (syn. T. ocellata) at Naples by Ruszkowski (I931, p. 163), and also from the heart and urinogenital system of this host, the specimens being identified by Ruszkowski as Chatin's 'Amphibdella torpedinis'.

At about the same time that Parona \& Perugia discovered the amphibdellid without a transverse bar on the parietal mucosa of the gills of Torpedo torpedo at Genoa, Monticelli (I890) recorded under the name of 'Tetraonchus torpedinis Chatin' what is probably a second species (with a transverse bar) from the same host species Torpedo torpedo (syn. T. narce) at Naples; this same species was probably recorded again from the same host $T$. torpedo (syn. T. ocellata) at Naples by Ruszkowski (I93I, footnote to p. I64). Monticelli referred to the presence of two transverse bars, but in this he almost certainly made a mistake similar to that made by Parona \& Perugia (I890) and referred to above. Thus it is highly desirable that the gills of $T$. torpedo be searched again for a second species of amphibdellid and that the parasite be described in detail.

MacCallum (I9I6) discovered two species of amphibdellids on the gills of T. nobiliana (syn. Tetranarce occidentalis) from Woods Hole, U.S.A., and identified one of them (with a transverse bar!) as Chatin's Amphibdella torpedinis and the other (without a transverse bar) as a new species $A$. flavolineata. Johnston \& Tiegs (I922) proposed a new species A. maccallumi for MacCallum's specimens of ' $A$ torpedinis' and later Price (1937) made this species the type of a new genus Amphibdelloides characterized by the presence of a transverse bar. In the course of the present study MacCallum's specimens have been borrowed from the United States National Helminthological Collection and have been compared with specimens of A. maccallumi and Amphibdella flavolineata from the same host Torpedo nobiliana captured in Europe (Plymouth, Irish Sea, Irish Atlantic Slope, and Mediterranean), and have been found to be identical. It is concluded that Price's recognition of two distinct genera according to the presence or absence of a transverse bar is basically sound, but that Price's second character, namely, that concerning the lobing of the posterior adhesive apparatus, needs considerable modification. Such a modification, together with some new generic characters, is proposed on pp. 580-2.

Palombi (I949), in his review of trematodes from Italy, regarded all amphi- 
bdellids previously recorded from Mediterranean hosts as belonging to one species Amphibdella torpedinis in which a transverse bar was constantly present and distinct in small specimens, but absent from large specimens.

Recently Alexander (1954) has recorded and redescribed Amphibdelloides maccallumi from Torpedo californica from California. I have compared some of Alexander's actual specimens with MacCallum's specimens and also with specimens of Amphibdelloides maccallumi from Torpedo nobiliana (i.e. the same host species as that from which MacCallum's material was collected) from various European localities, but can find no significant differences between any of them. Then in spite of the strongly suggestive evidence from the difference in host species and the difference in geographical distribution, on morphological grounds the amphibdellids with a transverse bar from $T$. californica and T. nobiliana must both be recognized as Amphibdelloides maccallumi. The inference from this parasitological evidence is that the divergence between Torpedo californica and $T$. nobiliana took place very recently, and support is thus given to the view of Fraser-Brunner (1949) who placed both $T$. nobiliana and $T$. californica in the subgenus Tetronarce, whereas $T$. torpedo and $T$. marmorata were regarded as belonging to the subgenus Torpedo.

Hargis (1955) described a new species Amphibdelloides narcine from Narcine brasiliensis from the Gulf of Mexico, and Euzet (1957) described the oncomiracidium of what he regarded at that time as Amphibdelloides maccallumi from the gills of Torpedo marmorata and T. nobiliana but which the present study has shown might properly belong either to A. maccallumi or to the new species $A$. vallei.

Bychowsky (1957) in surveying the systematics of the Monogenea, found previous work on amphibdellids to be inaccurate and contradictory, and in an attempt to clear up the confusion, studied specimens, some of them living, from Torpedo marmorata, $T$. torpedo (syn. T. ocellata), $T$. californica and T. smithi. He confirmed the observations of Ruszkowski and Palombi that there were sixteen hooklets on the haptor, and properly emphasized the phylogenetic significance of this observation. But Bychowsky refuted Price's (1937) recognition of two amphibdellid genera separated from each other by the presence or absence of a transverse bar and by the lobed or unlobed condition of the haptor, claiming that a transverse bar was always present but that it may be inconspicuous in older specimens, and that the lobing of the haptor could be greatly affected by histological fixation. The present study of the functional morphology of the adhesive apparatus has shown that the transverse bar is an integral part of the adhesive apparatus of those amphibdellids which hook themselves to secondary gill lamellae, and that it is absent from those amphibdellids which 'root' themselves subcutaneously in the gill mucosa. Thus Price's view that the presence or absence of the transverse bar was of taxonomic significance was well-founded. At the same time the 
present study agrees with Bychowsky's rejection of the second generic character used by Price, namely, the alleged unlobed condition of the haptor in Amphibdelloides. In place of Price's recognition of two genera of Amphibdellidae based on two characters (one of which was mis-interpreted), and of Bychowsky's recognition of a single genus, the present study accepts the same two genera as those accepted by Price, but on a basis of at least six contrasting characters, only one of which had been used by Price.

\section{PHYLOGENY}

On the basis of the above comparative morphological and taxonomic studies of the Amphibdellidae it is proposed now to speculate on the probable lines of evolutionary development within the group.

On the grounds of the very widespread occurrence of modern Tetraonchideans on the secondary gill lamellae of their hosts it may be assumed that the ancestral amphibdellid lived in a similar micro-habitat. It was attached to its host by a haptor provided with sixteen hooklet-bearing lobes, a posterior gland, and two pairs of unsupported hooks (i.e. without a transverse bar) operated by extrinsic muscles and tendons threaded through loops on the ventral hooks; such a haptor survives with least change in the present-day Amphibdella torpedinis and $A$. paronaperugiae. The male copulatory apparatus consisted of a pair of opposable sclerites, one on the left with a hook, and one on the right consisting of a simple bar, with the penis lying freely between them.

The dominating environmental hazard was the gill ventilating current of the host, and the parasite began to meet the problem in two different ways. One way was to make the hook apparatus more efficient by developing an accessory transverse supporting bar (the ancestral Amphibdelloides); the other was to relieve the hooks of some of their burden by 'rooting' the haptor subcutaneously in the host (the ancestral Amphibdella). In the second method it was an advantage to move from the relatively thin and delicate secondary lamellae to the more robust adjacent mucosa.

The dominating evolutionary trend now became towards increased efficiency of the copulatory apparatus. This took the form of a closer association of the penis with one of the accessory sclerites so that the latter acted as a guide. However, in the diverging Amphibdelloides and Amphibdella stocks different sclerites were used for the development of such a guide: in Amphibdelloides the left, hooked sclerite became the guide, with the penis emerging from the side of the sclerite, but in Amphibdella the right sclerite became tubular with the penis emerging through its distal end, the left sclerite retaining its more primitive function of acting as an opposable hook. Associated with these divergences in the male copulatory organs were some changes in the female copulatory organs: in Amphibdella the vaginal opening became ventro- 
lateral, but in Amphibdelloides it became dorso-lateral. Larval or juvenile forms of Amphibdella now took to invading the blood system of the host, perhaps to provide greater opportunities for cross-fertilization among its protandrous developmental stages (see p.579), perhaps to facilitate taking up the definitive manner of attachment (see P1. II, fig. 2), or perhaps merely to provide a relatively sheltered environment for larval development.

At this stage there was a divergence in the host stock, on the one hand (Fraser-Brunner, 1949) into Tetronarce (from which the modern Torpedo nobiliana and $T$. californica have descended) and on the other into Torpedo which has given rise to the present-day $T$. torpedo and $T$. marmorata. The gills of $T$. nobiliana have become relatively large and support the relatively large parasites Amphibdella flavolineata and Amphibdelloides maccallumi, and those of Torpedo marmorata are relatively small and support the smaller parasites Amphibdella torpedinis and Amphibdelloides vallei.

Following this divergence in the ancestral torpedinid stock, no further speciation took place on the Tetronarce line of descent for a long time, and under these relatively stable conditions the amphibdelloid parasites became increasingly specialized. In Amphibdella flavolineata the haptor was buried more deeply in the host tissues, and some of the hooklet-bearing lobes became greatly expanded, simulating the roots of a tree in providing more efficient anchorage. The increase in the 'rooting' component of the adhesive apparatus was accompanied by a gradual decrease in the efficiency of the hook apparatus, and the muscles have become correspondingly simplified; moreover, the posterior gland was lost. While the haptor was evolving thus, the trumpet of the penis-bearing sclerite developed a roughened surface to maintain more secure coverage of the vaginal opening of the co-copulant. In Amphibdelloides maccallumi the main specializations were the acquisition of a fibrous pad in association with the vaginal opening, and the development of a 'catch' mechanism to lock the adductor muscles of the large hooks.

Accompanying the relatively recent speciation of the Tetronarce stock to give rise to the modern Torpedo nobiliana and T. californica, we would expect corresponding speciation among the amphibdellid parasites, but in the limited sample of parasites from the gill lamellae of $T$. californica there was no evidence for this; it is possible that an examination of a larger sample of fresh material from $T$. californica might reveal evidence of at least incipient speciation in Amphibdelloides maccallumi. No specimens of Amphibdella flavolineata have yet been recorded from Torpedo californica.

In the Torpedo line of host descent, speciation into T. marmorata and T. torpedo took place long enough ago to have allowed divergences to become manifest also in the amphibdellid parasites. Amphibdella torpedinis (without shoulders to its hooks and with a relatively simple vaginal aperture) from Torpedo marmorata differs from Amphibdella paronaperugiae (with shoulders to its hooks and with the terminal part of the vaginal sclerite enlarged) from 
Torpedo torpedo. No information is available yet about the divergences which may have occurred between the corresponding Amphibdelloides parasites: A. vallei is known from Torpedo marmorata but the parasite from the gill lamellae of $T$. torpedo has not yet been described.

The Director and Staff of the Plymouth Laboratory have very kindly made available to me most of the rather rare electric rays brought in by the research vessels in recent years, and as always have provided excellent working facilities; Dr Louis Euzet of Sète has made special collections of specimens for me and has given me much of his own material; and the following have either arranged loans or presented me with specimens: Dr C. G. Alexander of California, Dr W. J. Hargis of Virginia, Dr M. Sara of the University of Naples, Dr H. H. Williams of Cardiff, and the United States National Museum.

\section{SUPPLEMENTARY NOTE}

In April 1960, by kind permission of Prof. P. Mathias, I was able to visit the Station Biologique at Sète, where the following observations were made.

Torpedo marmorata. (a) A freshly killed specimen was found to have nine very active juvenile specimens of Amphibdella torpedinis in its heart; these parasites were seen to move in a leech-like manner.

(b) Sections of the heart of a young host, prepared by and kindly shown to me by $M$. André Raibaut, were seen to contain a pair of juveniles of $A$. torpedinis in copulation.

Torpedo torpedo. (a) A single preserved specimen (caught at Sète in November 1959) was found to bear over fifty adult specimens of Amphibdella paronaperugiae all resembling exactly the specimens collected by Parona \& Perugia and described in the paper above; all these parasites were deeply embedded in the proximal gill mucosa as described and illustrated above for $A$. flavolineata.

(b) In the heart of the same host specimen were three juveniles of $A$.paronaperugiae, but no adults.

(c) No amphibdellids were found on the secondary gill lamellae.

\section{SUMMARY}

Comparative studies of the functional morphology of the adhesive organs and the genitalia of amphibdellid parasites from various micro-habitats on five species of electric rays have resulted in the proposal of several taxonomic revisions.

The family name Amphibdellidae has been substituted for the 'Amphibdellatidae' of Bychowsky, with an amended diagnosis. Revised diagnoses have been give also for the genera Amphibdella Chatin and Amphibdelloides Price, and specific diagnoses for Amphibdella torpedinis Chatin, A. flavolineata MacCallum, A. paronaperugiae n.sp., Amphibdelloides maccallumi (Johnston \& Tiegs), $A$. vallei n.sp., and $A$. narcine Hargis.

Amphibdella spp. live partly embedded subcutaneously in the gill mucosa of 
their hosts, and Amphibdelloides spp. hooked to the secondary lamellae; there are corresponding differences in the basically complex adhesive apparatus.

There is strong evidence that juvenile development in Amphibdella involves a protandrous form living endoparasitically in the blood system of the host.

Speculations have been made on the phylogeny of the group.

\section{REFERENCES}

AlEXANDER, C. G., I954. Microcotyle macracantha n.sp., a monogenetic trematode from the Gulf of California, with a redescription of Amphibdelloides maccallumi (Johnston \& Tiegs, 1922) Price, 1937. F. Parasit., Vol. 40, pp. 279-83.

Bigelow, H. B. \& Schroeder, W. C., I953. Fishes of the Western North Atlantic. New Haven: Sears Foundation for Marine Research Yale University, Memoir No. I, Part 2.

Bychowsкy, B. E., 1957. Monogenetic Trematodes, their Classification and Phylogeny. 509 pp. Moscow: Leningrad. Academy of Sciences, U.S.S.R.

Chatin, J., I874. Études sur des helminthes nouveaux ou peu connus. Ann. Sci. nat., Paris, Zool., Sér. 6, T. I, I8 pp.

EUZET, L., I957. Recherches sur les Monogenoidea parasites de poissons marins. Ann. Parasit. hum. comp., T. 32, pp. 469-8I.

Fraser-Brunner, A., 1949. Note on the Electric Rays of the genus Torpedo. Ann. Mag. nat. Hist., Ser. 12, Vol. 2, pp. 943-7.

HaRgIs, W. J., I955. Monogenetic trematodes of Gulf of Mexico fishes. Part I. The superfamily Gyrodactyloidea. Biol. Bull., Woods Hole, Vol. 108, pp. I25-37.

Johnston, T. H. \& Tiegs, O. W., 1922. New gyrodactylid trematodes from Australian fishes, together with a reclassification of the superfamily Gyrodactyloidea. Proc. Linn. Soc. N.S.W., Vol. 47, pp. 83-13I.

LlewELlyN, J., I957. Host specificity in monogenetic trematodes. In: First Symposium on Host Specificity among Parasites of Vertebrates, pp. I9I-212. Neuchâtel.

MacCallum, G. A., I9I6. Some new species of parasitic trematodes from marine fishes. Zoopathologica, Vol. I, pp. 3-38.

Monticelli, F. S., I890. Note elmintologiche. Boll. Soc. Nat. Napoli, Vol. 4, pp. I89-208.

OwEN, G., I955. Use of propylene phenoxetol as a relaxing agent. Nature, Lond., Vol. 175, p. 434.

Palombi, A., I949. I trematodi d'Italia-Parte I. Trematodi monogenetici. Arch. zool. (ital.), Napoli, Vol. 34, pp. 203-408.

Parona, C. \& Perugia, A., I890. Nuove osservazioni sull'Amphibdella torpedinis Chatin. Ann. Mus. Stor. nat. Genova, Ser. $2 a$, Vol. 9, pp. 363-7.

Perugia, A. \& Parona, C., I89o. Di alcuni trematodi ectoparassiti di pesci adriatici. Ann. Mus. Stor. nat. Genova, Ser. 2a, Vol. 9, pp. 16-32.

PrICE, E. W., I937. North American monogenetic trematodes. I. The superfamily Gyrodactyloidea (Cont.). F. Wash. Acad. Sci., Vol. 27, pp. I46-64.

REES, G. \& LlEWELLYN, J., I94I. A record of the trematode and cestode parasites of fishes from the Porcupine Bank, Irish Atlantic Slope, and Irish Sea. Parasitology, Vol. 33, pp. 390-6.

Ruszkowski, J. S., 1931. Sur la découverte d'un ectoparasite Amphibdella torpedinis dans le cœur des torpilles. Pubbl. Staz. zool. Napoli, Vol. I I, pp. I6I-7.

SMITH, H. W., I936. The retention and physiological role of urea in the Elasmobranchii. Biol. Rev., Vol. II, pp. 49-82. 

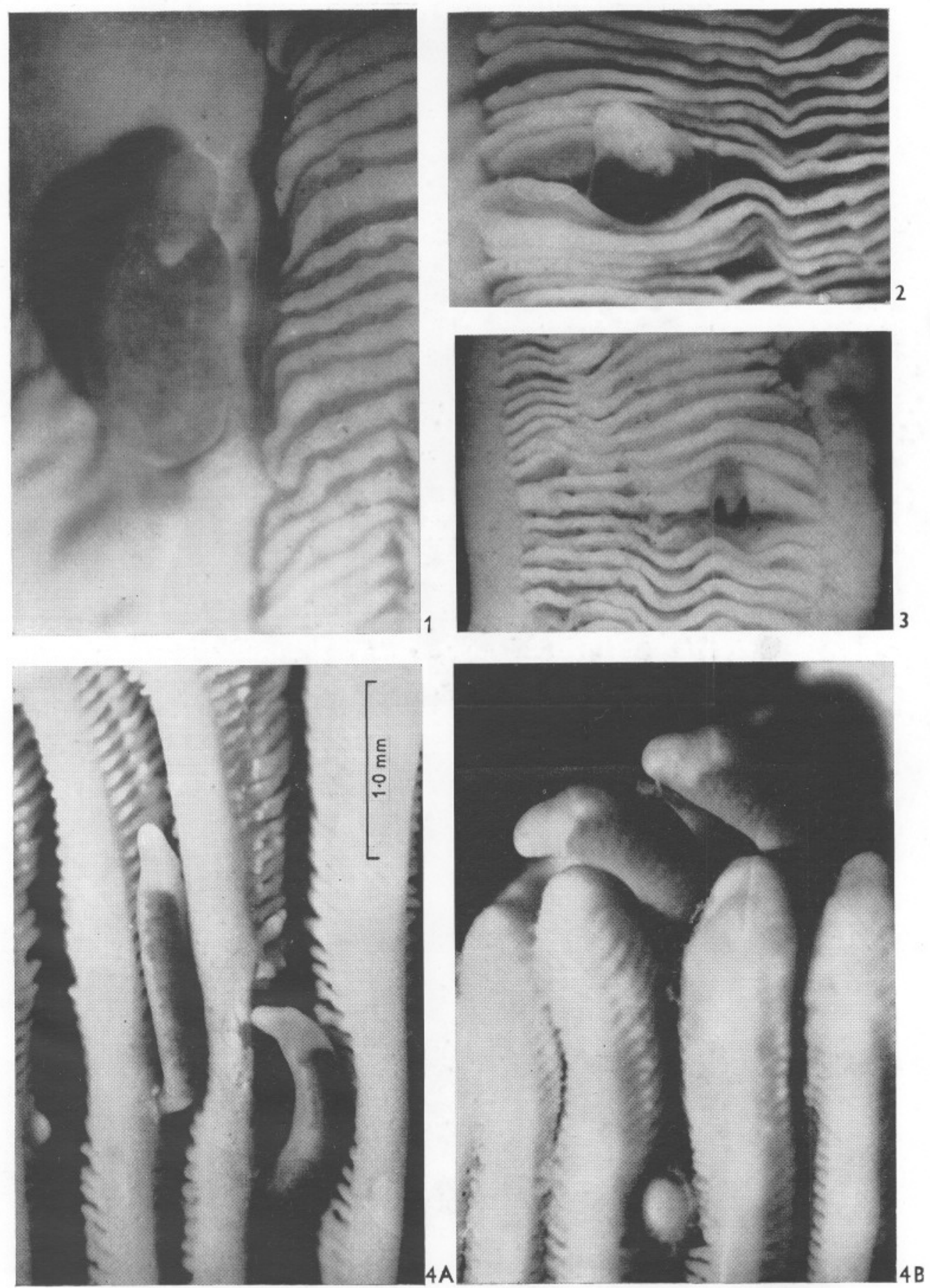

(Facing p. 588) 

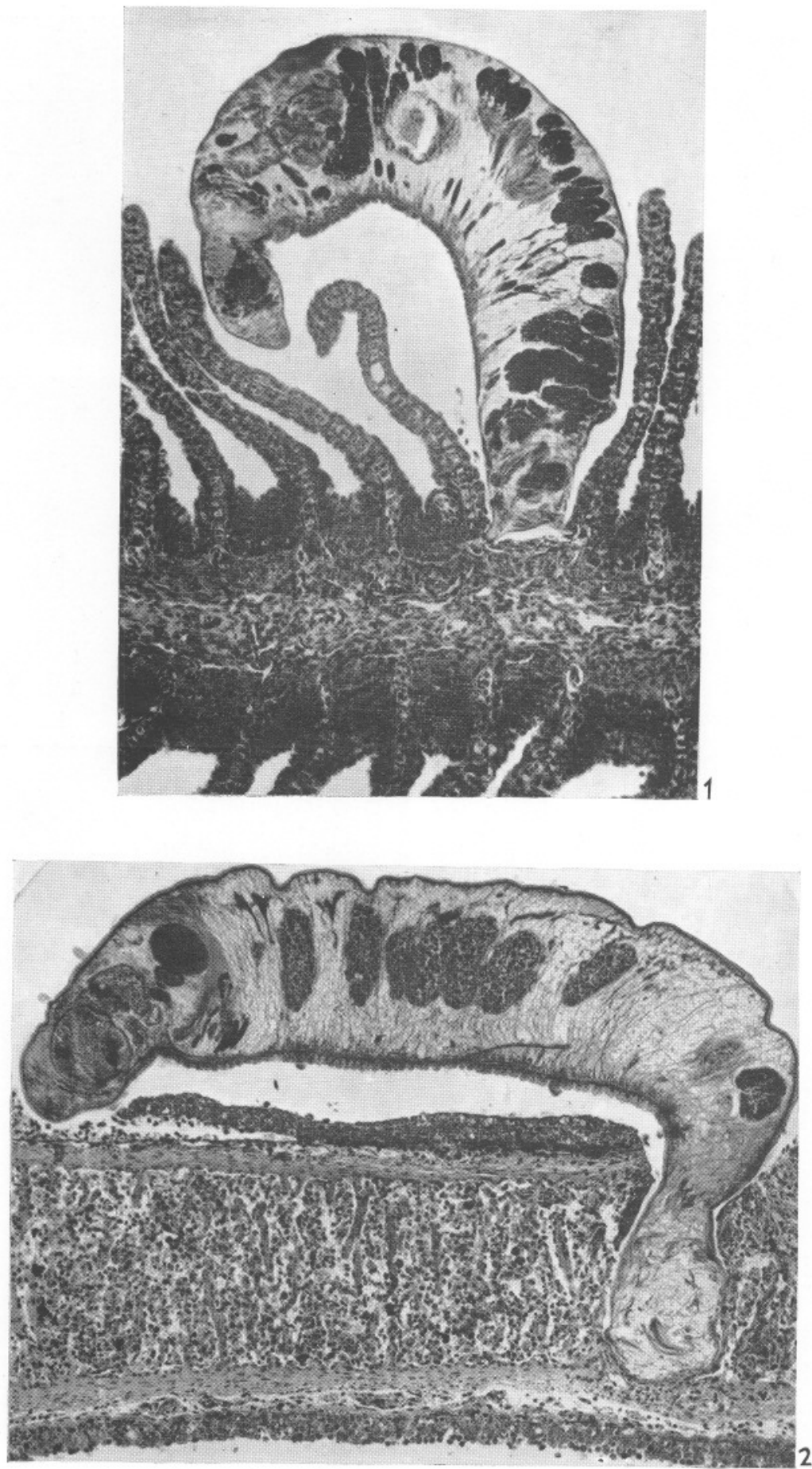

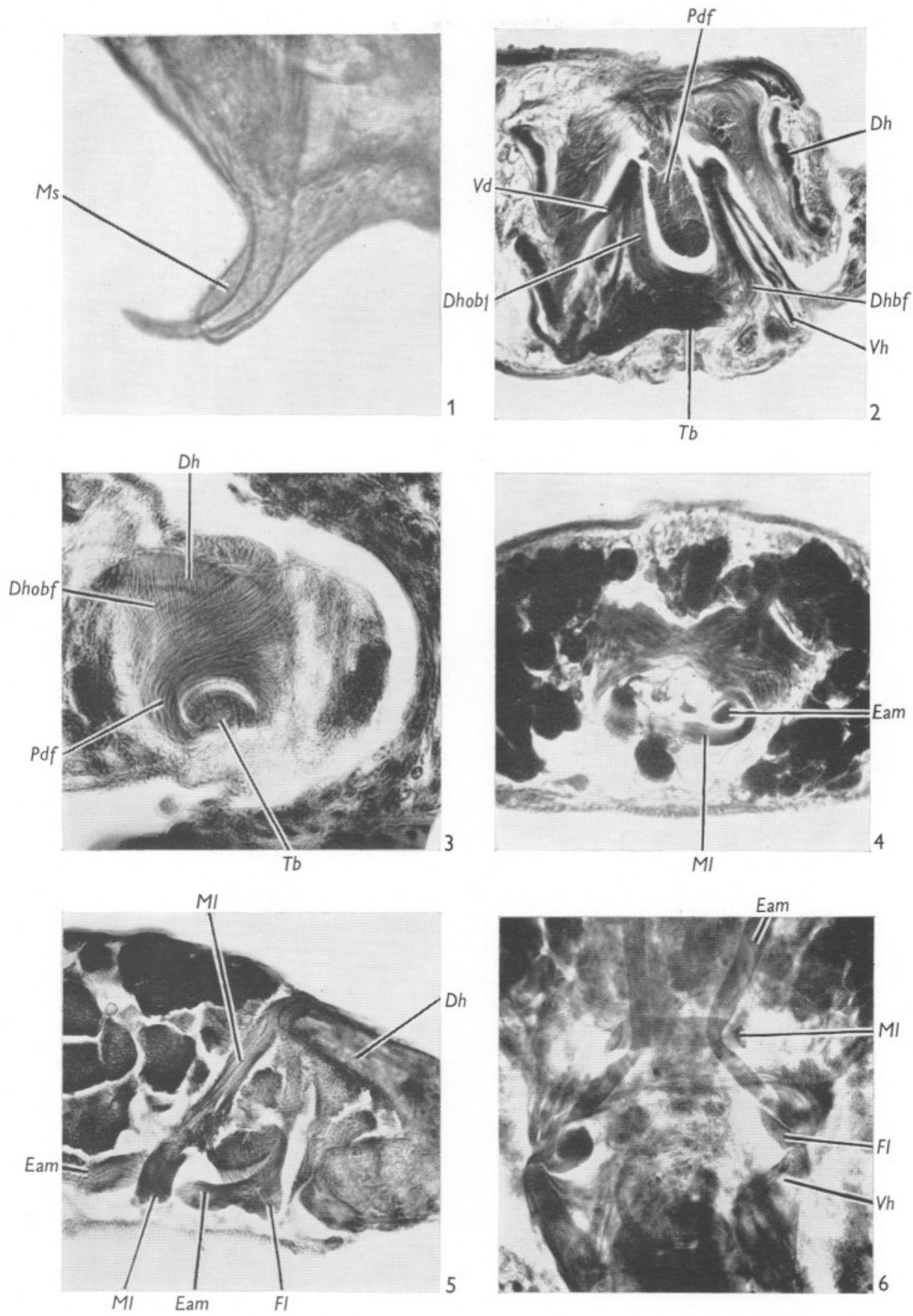


\section{EXPLANATION OF PLATES}

Plate I

The micro-habitats of amphibdellids.

(All photographs to the same scale.)

Fig. I. Amphibdella flavolineata on the gill mucosa of Torpedo nobiliana. Fig. 2. Amphibdelloides maccallumi on the secondary gill lamellae of Torpedo nobiliana. Fig. 3. Amphibdelloides vallei on the secondary gill lamellae of Torpedo marmorata. Figs. 4A, B. Amphibdella torpedinis on the gill mucosa of Torpedo marmorata; $4 \mathrm{~A}$, two specimens on the distal, free border of a primary lamella; $4 \mathrm{~B}$, three specimens on the proximal mucosa adjacent to the gill arch.

\section{Plate II}

The attachment of amphibdellids to their hosts.

Fig. I. Amphibdelloides maccallumi hooked to the secondary gill lamellae of Torpedo nobiliana. Fig. 2. Amphibdella flavolineata 'rooted' subcutaneously in the gill mucosa of Torpedo nobiliana.

\section{Plate III}

The hook apparatus of Amphibdelloides maccallumi.

For explanation of lettering see text pp. 566-9 and compare with Text-fig. 7. Fig. I. The muscle sheath surrounding the base of the curved part of the hook. Living specimen. Figs. 2-5. Paraffin sections of haptor. Fig. 2. Transverse section in plane of transverse bar. Fig. 3. Sagittal section. Fig. 4. Transverse section at level of median loop. Fig. 5. Parasagittal section in plane of dorsal hook. Fig. 6. Balsam preparation of whole specimen stained in chlorocarmine. 